ORIGINAL ARTICLE

\title{
Management of acute cholecystitis in UK hospitals: time for a change
}

\author{
I C Cameron, C Chadwick, J Phillips, A G Johnson
}

Postgrad Med J 2004;80:292-294. doi: 10.1136/pgmi.2002.004085

See end of article for authors' affiliations

....................

Correspondence to: Mr lain C Cameron, University Surgical Unit, Royal Hallamshire Hospital, Sheffield S10 2JF, UK; cameron_iain@ hotmail.com

Submitted

10 December 2002

Accepted

10 September 2003 cute cholecystitis is safe, cost effective, and leads to less time off Early cholecystectomy for patients with acute cholecystitis is safe, cost effective, and leads to less time off
work compared with delayed surgery. This study was designed to assess current practice in the management of acute cholecystitis in the UK. A postal questionnaire was sent to 440 consultant general surgeons to ascertain their current management of patients with acute cholecystitis. Replies were received from 308 consultants who were involved in treating patients with acute cholecystitis of whom 18 transferred these patients on to another team for further management the day after admission. Thirty two consultants (1 1\%) routinely treated patients by early cholecystectomy, with limiting factors stated to be the availability of surgical staff, theatre space, and radiological investigations. The remaining consultants $(n=258)$ routinely manage their patients conservatively with intravenous antibiotics and allow the inflammation to resolve before undertaking cholecystectomy at a later date. Indications for undertaking early cholecystectomy during the first admission by this latter group included the presence of spreading peritonitis due to bile leak, empyema, and unexpected space on theatre list. The commonest method for both elective and early cholecystectomy is laparoscopic, but the percentage of consultants using an open method rises from $8 \%$ in the elective situation to $47 \%$ for urgent early cholecystectomy. Despite evidence which strongly advocates early cholecystectomy, this practice is routinely carried out by only $11 \%$ of consultants in the UK at present.
$\mathrm{O}$ pinions among surgeons regarding the optimum management of acute cholecystitis remain divided. Some advocate early cholecystectomy during the initial admission, whereas others prefer to treat patients conservatively in the first instance with intravenous fluids and antibiotics and undertake delayed elective cholecystectomy. Two randomised controlled trials of early versus delayed laparoscopic cholecystectomy in the management of acute cholecystitis have both shown early laparoscopic cholecystectomy to be safe and associated with lower rates of conversion and reduced total hospital stay compared with delayed surgery. ${ }^{12}$ In addition, the hazards of conservative management of acute cholecystitis in the UK, especially with regard to patient readmissions, have recently been highlighted. $^{34}$ The aim of this study therefore was to assess current practice in the management of acute cholecystitis by general surgeons in the UK.

\section{METHODS}

A postal questionnaire was sent to 440 consultant general surgeons. They were asked to provide details of their on-call commitments, subspecialist interests, and the management of patients under their care with acute cholecystitis. In particular they were asked whether they routinely opted for early cholecystectomy during the first admission or preferred initial conservative management and delayed interval cholecystectomy. Surgeons opting for early cholecystectomy were asked which factors limited this practice, with those opting for conservative management being asked in which situations they would undertake early surgical intervention. All surgeons were asked about their chosen method of cholecystectomy in the early and delayed setting.

\section{RESULTS}

Replies were received from 317 surgeons (72\%) of whom nine stated that they were no longer involved in general surgical emergency work. A total of 308 consultants were in a general surgical on-call rota and therefore had patients with acute cholecystitis admitted under their care. Surgeons were asked for details of their area of subspecialist interest, with 182 consultants $(60 \%)$ declaring only one subspecialist interest, the most popular of which was colorectal $(n=60)$ closely followed by vascular $(\mathrm{n}=48)$ and upper gastrointestinal $(\mathrm{n}=45)$. Ninety seven declared two subspecialist interests $(31 \%)$, of which the most popular combinations were colorectal/breast $(n=26)$, colorectal/upper gastrointestinal $(\mathrm{n}=23)$, and breast/endocrine $(\mathrm{n}=15)$. Twenty nine surgeons declared either three or four subspecialist interests and in total there were 32 different combinations of subspecialist interests. Eighteen consultants $(5.8 \%)$ stated that the day after admission they referred patients with acute cholecystitis on to a colleague for further management.

The remaining 290 surgeons treated patients with acute cholecystitis throughout their initial admission. Early cholecystectomy during the first admission is the preferred method of management of 32 consultants ( $11 \%$ ), with 25 performing early surgery laparoscopically $(78 \%)$ and the rest using an open surgical technique. Seventeen (53\%) declared upper gastrointestinal as their only subspecialist interest and a further eight $(25 \%)$ included upper gastrointestinal as one of two subspecialist interests. They were asked what they regarded as the limiting factors to this practice, with the three most commonly stated reasons being the availability of surgical staff $(n=17)$, theatre space, $(n=10)$ and radiological investigations $(n=6)$.

The majority of general surgeons (89\%), however, preferred initial conservative management with intravenous fluids and antibiotics. Delayed cholecystectomy is then undertaken at a later date, provided that the initial attack of acute cholecystitis settles. Patients are either booked directly for surgery $(n=133)$, seen and reassessed as outpatients $(n=80)$, either of the first two depending on the individual patient $(n=24)$ or referred on to a colleague with an upper gastrointestinal interest $(n=21)$. The timing 


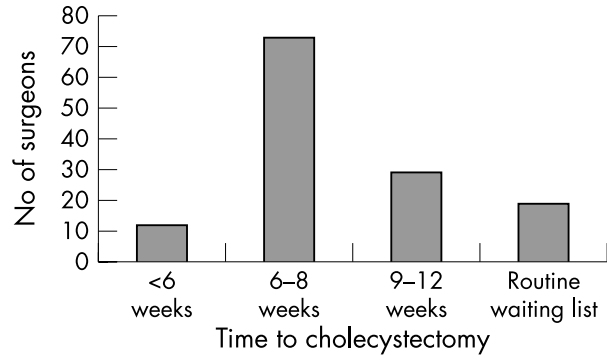

Figure 1 Consultant preference regarding the timing of delayed cholecystectomy in patients discharged after an episode of acute cholecystitis.

of subsequent elective cholecystectomy varied from four weeks after hospital discharge, to being placed on the routine waiting list, which is surprising in view of the well recognised problems these patients encounter with recurrent symptoms and hospital readmissions if surgery is delayed significantly. The number of consultants choosing various options with regard to the timing of delayed cholecystectomy are shown in fig 1. The conservative treatment group would, however, perform early cholecystectomy during the initial admission in certain circumstances, including development of peritonitis due to a bile leak (94\%), empyema (91\%), unexpected space on an elective theatre list $(27 \%)$, and failure of the acute episode to settle within a few days $(21 \%)$. Laparoscopic is the more popular method of cholecystectomy for both the delayed elective and urgent surgery, but the percentage of consultants performing open surgery rises dramatically in the latter situation. The percentages of surgeons performing laparoscopic and open cholecystectomy in the groups routinely performing either urgent, early, or delayed elective cholecystectomy are shown in fig 2 .

Overall, 39 consultants (12.7\%) stated that they referred patients with acute cholecystitis on to a colleague for further management, with 18 doing this the day after admission and the remainder doing it on discharge, after conservative management of the episode of acute cholecystitis. The subspecialist interests of consultants who refer their patients on to a colleague are shown in table 1 .

\section{DISCUSSION}

This study indicates that acute cholecystitis is, at present, a condition managed by general surgeons with widely differing subspecialist interests. Only $12.7 \%$ of the consultants who responded refer their patients with acute cholecystitis to a different team for further management and of these 19 stated breast surgery as a subspecialist interest and 18 vascular surgery. However, the majority of surgeons with a breast or vascular interest treat their own patients with cholecystitis and often undertake cholecystectomy. Only six out of 137 surgeons declaring a colorectal interest refer their patients on to an upper gastrointestinal surgeon. These data indicate that at present acute cholecystitis remains a condition managed by generalist rather than specialist surgeons, and that cholecystectomy is still undertaken by many general surgeons.

Early cholecystectomy is the routine practice of only $11 \%$ of general surgeons who manage this condition. Several studies conducted in the prelaparoscopic era demonstrated the advantages of early cholecystectomy, ${ }^{56}$ indicating that it was more cost effective and allowed a quicker return to normal activity. However, after the evolution of laparoscopic cholecystectomy, enthusiasm for early cholecystectomy waned after several reports of complications associated with this practice. ${ }^{7-10}$ These concerns have been allayed by several papers indicating that early surgery is safe and identifying

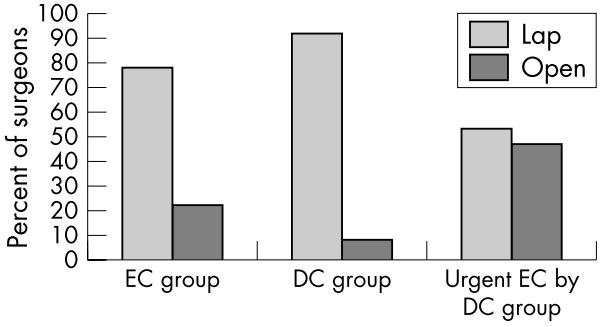

Figure 2 Percentages of surgeons performing open and laparoscopic (Lap) cholecystectomy in different situations (DC, delayed cholecystectomy; EC, early cholecystectomy).

Table 1 Subspecialist interests of consultants who refer on patients with acute cholecystitis

\begin{tabular}{ll}
\hline Subspecialist interest & No of consultants \\
\hline Vascular & 12 \\
Breast & 9 \\
Breast/endocrine & 6 \\
Colorectal & 5 \\
Breast/vascular & 4 \\
Vascular/endocrine & 2 \\
Colorectal/paediatric & 1 \\
\hline
\end{tabular}

factors associated with a successful outcome after early laparoscopic cholecystectomy for acute cholecystitis. ${ }^{11-15}$ Only one trial to date has compared early laparoscopic with early open cholecystectomy, the results showing reduced total hospital stay, time off work, and complication rate with laparoscopic surgery. ${ }^{15}$ The two randomised controlled trials comparing early against delayed laparoscopic cholecystectomy in acute cholecystitis have both shown early surgery to be safe, more cost effective, and associated with a lower conversion rate than delayed surgery. ${ }^{12}$ Conservative management was associated with a total hospital stay almost double of those treated by early cholecystectomy, and the additional problem of over $25 \%$ of patients being readmitted to hospital with further symptoms before definitive surgery has been reported recently. ${ }^{34}$

Why therefore do only $11 \%$ of surgeons routinely undertake early cholecystectomy, a practice that is widespread in North America, Asia, Australasia, and in some parts of Europe. Those who favour early surgery stated that the limiting factors to this practice included the lack of availability of experienced surgeons due to other clinical and management commitments and the limited availability of theatre space. Most hospitals now have a dedicated daytime emergency theatre in which early cholecystectomy could be undertaken but there is often a problem with surgeon availability due to clashes with elective theatre sessions and outpatient clinics. This problem could be avoided by a system whereby one consultant is on-call for general surgery for all or part of a week, during which time they have no elective lists or outpatient sessions. This would allow early surgery for patients admitted with acute cholecystitis or biliary colic, as an experienced surgeon would be available to operate in the daytime emergency theatre.

The reasons why early cholecystectomy is not commonly undertaken in the UK at present include a lack of experienced surgeon availability and problems with the availability of both emergency theatre time and radiological investigations. Altogether $27 \%$ of the consultants who prefer initial conservative management stated that they would be happy to undertake early cholecystectomy if unexpected space appeared on the elective theatre list. Within the 
conservative treatment group, a far greater percentage of surgeons undertake cholecystectomy laparoscopically in the elective situation (92\%) than do so in the early or urgent situation $(53 \%)$, and this may contribute to the lack of enthusiasm for early surgery. Overall 80 surgeons declared an upper gastrointestinal interest, of whom 26 (32.5\%) routinely undertake early cholecystectomy and a further 31 (39\%) indicated that they would do so if unexpected space appeared on their theatre list. Therefore 57 of the 80 upper gastrointestinal surgeons $(71 \%)$ are prepared to undertake early cholecystectomy where this is practical, indicating that they are more willing to undertake this procedure than those who were not upper gastrointestinal specialists.

The present generation of higher surgical trainees are already undertaking a programme of training geared towards their chosen subspecialist field, with limited exposure to elective surgery outside this area. The consultants of the future are therefore unlikely to undertake biliary surgery unless they have an interest in upper gastrointestinal or hepatobiliary surgery, as their experience of this as a trainee will be restricted. This may eventually lead to acute cholecystitis becoming the domain of the specialist rather than the generalist, and with this the expectation that the gold standard management of acute cholecystitis, namely planned early cholecystectomy, will become common practice in the UK.

\author{
Authors' affiliations \\ I C Cameron, C Chadwick, J Phillips, A G Johnson, University Surgical \\ Unit, Royal Hallamshire Hospital, Sheffield, UK
}

\section{REFERENCES}

1 Lai PBS, Kwong KH, Leung KL, et al. Randomized trial of early versus delayed laparoscopic cholecystectomy for acute cholecystitis. Br J Surg 1998;85:764-7.

2 Lo C-M, Liu C-L, Fan S-T, et al. Prospective randomized study of early versus delayed laparoscopic cholecystectomy for acute cholecystitis. Ann Surg 1998;227:461-7.

3 Cameron IC, Chadwick C, Phillips J, et al. Acute cholecystitis-room for improvement? Ann R Coll Surg Engl 2002;84:10-13.

4 Cheruvu CVN, Eyre-Brook IA. Consequences of prolonged wait before gallbladder surgery. Ann R Coll Surg Engl 2002;84:20-2.

5 Jarvinen HJ, Hastbacka J. Early cholecystectomy for acute cholecystitis. A prospective randomized study. Ann Surg 1980;191:501-5.

6 Norrby S, Herlin P, Holmin T, et al. Early or delayed cholecystectomy in acute cholecystectomy in acute cholecystitis? A clinical trial. Br J Surg 1983;70:163-5.

7 Kum CK, Eypasch E, Lefering R, et al. Laparoscopic cholecystectomy for acute cholecystitis: is it really safe? World J Surg 1996;20:43-9.

8 Russell JC, Walsh SJ, Mattie AS, et al. Bile duct injuries, 1989-1993. A statewide experience. Conneiticut Laparoscopic Cholecystectomy Registry. Arch Surg 1996;131:382.

9 Branum G, Schmitt C, Baillie J. Management of major biliary complications after laparoscopic cholecystectomy. Ann Surg 1993;217:532-40.

10 Bender JS, Zenilman ME. Immediate laparoscopic cholecystectomy as definitive therapy for acute cholecystitis. Surg Endosc 1995;9:1081-4.

11 Flowers JL, Bailey RW, Scovill WA, et al. The Baltimore experience with laparoscopic management of acute cholecystitis. Am J Surg $1991 ; 161: 388-92$

12 Lujan JA, Parilla P, Robles R, et al. Laparoscopic cholecystectomy in the treatment of acute cholecystitis. J Am Coll Surg 1995;181:75-7.

13 Eldar S, Sabo E, Nash E, et al. Laparoscopic cholecystectomy for acute cholecystitis: prospective trial. World J Surg 1997;21:540-5.

14 Cox MR, Wilson TG, Luck AJ, et al. Laparoscopic cholecystectomy for acute inflammation of the gallbladder. Ann Surg 1993;218:630-4.

15 Kiviluoto T, Siren J, Luukhonen $\mathrm{P}$, et al. Randomised trial of laparoscopic versus open cholecystectomy for acute and gangrenous cholecystitis. Lancet 1998;347:321-5. 